\title{
A organização da informação nos sites das TVs universitárias públicas brasileiras
}

\author{
José Carlos Mardegan \\ Mestre; Universidade Estadual de Londrina; \\ mardegan@uel.br \\ Brígida Maria Nogueira Cervantes \\ Doutora; Universidade Estadual de Londrina \\ brigidacervantes@gmail.com
}

Resumo: O estudo analisa a organização da informação em sites de televisões universitárias públicas brasileiras e investiga a quantidade de TVs presentes no segmento das Instituições de Ensino Superior (IES) públicas e, dentre elas, quais utilizam a internet para a difusão do conteúdo produzido. A pesquisa é documental, exploratória e descritiva com abordagem quantiqualitativa. O resultado apresenta um total de 102 IES, 42,2\% delas produzem televisão e, destas, mais da metade utilizam a internet como meio de difusão. Conclui que os sites das TVs não apresentam os requisitos mínimos necessários de organização que possibilite uma armazenagem e recuperação da informação de modo eficiente.

Palavras-chave: Organização da informação em sites. TV universitária. Documento audiovisual. Documento televisual.

\section{Introdução}

A informação é uma necessidade do indivíduo provocada por fatores sociais e culturais (HJØRLAND, 2002). Buckland (2011) afirma que o uso da informação e o comportamento informacional estão relacionados com o indivíduo que deseja e precisa ser informado.

$\mathrm{O}$ avanço das tecnologias digitais e o surgimento da internet fizeram emergir um novo paradigma social, denominado por alguns autores, como sociedade da informação ou sociedade em rede consolidada na informação (CASTELLS, 2003). Miranda considera que a realidade contemporânea "[...] permitiu a eliminação das fronteiras e das barreiras para o acesso ao conhecimento produzido pela humanidade." (2005, p. 26). As Tecnologias da Informação e Comunicação (TIC) se fazem presentes nessa evolução e, neste processo, a televisão, juntamente 
com a internet, desempenham papel fundamental, levando informações para todas as partes do mundo. A televisão se transformou no principal meio de comunicação para os brasileiros devido à sua ampla cobertura e penetração em todas as camadas da população sendo, também, a principal fonte de informação para milhões de pessoas.

As Instituições de Ensino Superior (IES) produzem conhecimentos o tempo todo e, objetivando cumprir a missão social que lhes compete, utilizam a TV universitária como forma de disseminar a informação gerada no âmbito acadêmico, estreitando a comunicação com a sociedade onde o canal está inserido.

Considerando que grande parte das TVs universitárias utilizam a internet como meio de difusão da programação, a pesquisa tem como objetivo investigar as estruturas de organização da informação nos sites das TVs universitárias brasileiras ligadas às universidades públicas. Com base nos resultados obtidos foi possível verificar que as TVs universitárias não estão facilitando ao usuário o acesso às suas produções por meio da internet de forma rápida e eficiente.

\section{Televisão universitária no Brasil}

A universidade é um lugar

[...] privilegiado para conhecer a cultura universal e as várias ciências, para criar e divulgar o saber; mas deve buscar uma identidade própria e uma adequação à realidade nacional.” [Situase na] [...] esfera da superestrutura, dentro da Sociedade Civil, mantendo vínculos com a Sociedade Política e a base econômica. (WANDERLEY, 1988, p. 11).

Wanderley menciona que a universidade "Serve normalmente à manutenção do sistema dominante, mas pode também servir à transformação social.” (1988, p. 11).

Wanderley (1988), assegura ainda que o termo universidade está ligado a muitos outros, como, por exemplo: cultura, ciência, ensino superior, pesquisa, autonomia, entre outros, que devem ser conjuntamente compreendidos. O autor acrescenta ainda que algumas funções da universidade, “[...] como as de qualificar os mais aptos para as diversas profissões, diferenciar o saber científico e o précientífico, a cultura erudita e a popular, tornar a universidade mais democrática, [...]" e “[...] abri-la para as camadas mais vastas da população [...]", mesmo que problemáticas, configuram-se ainda como objetivos a serem alcançados pelas 
universidades (WANDERLEY, 1988, p. 7). As TVs universitárias desempenham indispensável papel estreitando o diálogo entre a instituição e a sociedade por meio da divulgação do conhecimento desenvolvido no âmbito acadêmico.

Apesar de ter sido um processo demorado, a universidade brasileira reconheceu a importância da televisão como campo de pesquisa e está abrindo suas portas para ela. Ramalho (2010, p. 52) afirma: “Assim como é necessária a compreensão da importância da TV Pública pela sociedade, a TV universitária igualmente busca seu reconhecimento por parte da comunidade acadêmica." A autora entende ainda que "Se esse meio quer dialogar com a sociedade, deve, primeiramente, comunicar-se com a sua comunidade." Eis aqui um enorme desafio tanto para a universidade quanto para a TV universitária (TVU).

Distinguir a TVU dentre as demais categorias de televisão é uma tarefa difícil, pois ela apresenta certo hibridismo na sua composição. Conceitualmente a TVU traz as características das emissoras públicas e educativas, mas tem a peculiaridade de envolver obrigatoriamente a universidade, isso agrega a ela características de TV Pública e de TV Educativa. As TVs universitárias podem ser transmitidas por meio de sinal aberto, via satélite, via cabo, pela internet e em circuitos fechados. Para todas as situações, com exceção do suporte on-line, precisam de concessão pública para funcionar e devem obedecer a legislações e regulamentações específicas (BACCO, 2010).

A Carta de Diretrizes das TVs Universitárias Brasileiras, elaborada pela Associação Brasileira de Televisão Universitária (ABTU) (2009), estabeleceu três dimensões para essas TVs: acadêmica, publicitária e política, dimensões estas que devem nortear o comportamento e a produção do seguimento nas IES.

$\mathrm{Na}$ dimensão acadêmica, que está relacionada com ensino, pesquisa e extensão, a TVU assume compromissos com a IES mantenedora, devendo ter total envolvimento com todas as áreas do conhecimento. O ideal é a universidade não apenas divulgar as notícias ocorridas no seu entorno, mas criar mecanismos e formas apropriadas para debatê-las com a comunidade. Como espaço de pesquisa, a TVU cria um significativo campo de experimentos de novos formatos e linguagens, diferenciando-se das TVs convencionais. É preciso ter coragem para ousar, inovar, sair dos velhos padrões (BRASIL, 2002). 
No que se refere à extensão, cabe à TVU contribuir para propagar, na sociedade, as teorias produzidas na academia, além de incentivar, apoiar e participar da produção de audiovisuais fornecendo know-how e, inclusive, espaço para a divulgação. A dimensão publicitária faz parte do cotidiano da TVU, já que projeta a instituição nos meios onde é veiculada. Muito embora a divulgação verdadeira das atividades das IES seja uma decisão essencial, que vem ao encontro dos anseios da sociedade, ela não deve ser considerada como atividade ou missão exclusiva da TVU, pois se trata de uma consequência da própria natureza da universidade, que se encerra em si mesma, como uma fonte permanente de informação (BACCO, 2010).

Por último, encontra-se a dimensão política da TVU, que está relacionada com a democratização da produção acadêmica, permitindo que o conhecimento teórico desenvolvido em sala de aula e laboratórios, entre outros espaços, seja compartilhado com a comunidade, priorizando a prestação de serviços e o desenvolvimento regional.

[...] é importante possibilitar que outros grupos da sociedade tenham acesso à divulgação de sua produção, levando a produção televisiva como recurso de inclusão digital e, conseqüentemente, à formação de telespectadores críticos. (RAMALHO, 2005, p. 49$50)$.

Os dirigentes e a comunidade universitária precisam estar atentos para a importância estratégica que a comunicação representa em relação à divulgação das atividades da instituição e à credibilidade política que a TVU pode agregar à informação. "[...] a comunicação televisiva pode revelar a contraface da excelência, que é a relevância. A qualidade dos cursos mostra a excelência, mas a produção televisiva mostra o trabalho da comunidade científica." (RAMALHO, 2005, p. 50). Por intermédio da TVU, pode-se traduzir a excelência, mostrar a vida cotidiana da universidade, construindo o sentido público da instituição.

\section{Organização da informação em sites}

A informação compreende uma unidade de três elementos: conhecimento - que é o conteúdo da informação; linguagem - constituído pelo instrumento de expressão de partículas de informação; e suporte - objetos físicos ou energia. A informação existe e desempenha sua função social por intermédio de um suporte físico, existe fora da 
consciência individual e independe dela, desde o momento de sua origem (FOGL, 1979).

Choo (2003) enumera três situações para o uso da informação: criar significado, construir conhecimento e tomar decisões. Afirma ainda que a informação passa a ter valor estratégico somente quando transformada em conhecimento pelas pessoas, o que, de maneira geral, provoca mudança em sua capacidade de agir. Entretanto, para que isso ocorra, "A informação deve ser ordenada, estruturada ou contida de alguma forma, senão permanecerá amorfa e inutilizável.” (McGARRY, 1999, p. 11). De acordo com o autor, a informação desestruturada, que não tenha passado por algum tipo de tratamento que viabilize sua recuperação posterior, será apenas um dado armazenado, deixando, dessa forma, de ser insumo para novos conhecimentos.

É impossível qualquer discussão acerca da organização da informação, mesmo tendo como suporte a web, sem que se faça alguma reflexão sobre conceitos básicos da área da Ciência da Informação (CI), dentre eles, o de documento. Svenonius (2000), quando afirma que informação é uma abstração e que os documentos que a contêm estão podem estar diferentes formatos, como papel ou arquivos digitais, conclui, também, que o documento é o suporte da informação.

Feitosa (2006, p. 17) afirma que "Um documento é um objeto que fornece um dado ou uma informação e pode ser diferenciado entre outros documentos, de acordo com suas características físicas ou intelectuais." As características físicas estão relacionadas com os conceitos de material, natureza, tamanho, peso, forma de produção e suporte, entre outras; já as características intelectuais dizem respeito aos conceitos de objetivo, conteúdo, assunto, tipo de autor, fonte, forma de difusão e originalidade, entre outras.

Para Fujita (2005, p. 8), o documento é “[...] a fixação da mensagem, a representação do conhecimento e o suporte para registro do conhecimento." Os documentos são "portadores de informações em forma de mensagens gravadas", assim como um "material ou uma representação dos pensamentos dos homens, por meio de alguma marca ou símbolo convencional." (SVENONIUS, 2000, p. 34).

Os documentos podem ser distinguidos, também, conforme sua natureza, podendo ser textuais e não textuais. Esta distinção determina o tipo de informação 
que eles podem transmitir, sendo que cada categoria compreende uma grande variedade de documentos (GUINCHAT; MENOU, 1994). Svenonius (2000) acrescenta, como exemplo de documentos, as imagens veiculadas pela internet. Portanto, os documentos também podem ser audiovisuais ou televisuais, visuais ou auditivos. Rubio (2003, p. 216) afirma que "O documento audiovisual, como documento científico, participa, consequentemente, das mesmas notas de informação e fonte informativa e se integra igualmente no processo informativo-documental.".

Para Goyanes (2005, p. 160), “[...] os documentos audiovisuais são um fenômeno relativamente recente no âmbito da documentação, sobretudo se comparados com a larga trajetória dos documentos textuais.”. A autora acrescenta que os documentos audiovisuais são considerados opacos, pois seu conteúdo não é legível ou acessível de forma direta, sempre haverá a necessidade de utilização de aparatos de leitura, o que os deixa dependentes de meios técnicos. Outro aspecto apontado é o fato de que os documentos audiovisuais são também multiformes e incompatíveis, ou seja, gravados em múltiplos suportes físicos e em diversos formatos.

Em decorrência dessas características dos documentos audiovisuais, Miranda e Garbelini (2011, p. 440) afirmam que,

[...] provavelmente, estes documentos não são tratados tecnicamente pela maioria dos profissionais da informação por serem muito mais complexos na sua natureza e produção de se fazer um tratamento técnico eficiente, ou seja, classificar, indexar $\mathrm{e}$, consequentemente, armazenar.

A decisão de criar um site na web deve levar em conta o propósito e os objetivos a serem alcançados, tais valores são de grande importância para moldar e direcionar as decisões e servem de base também para traçar estimativas de sucesso. No entanto, alguns objetivos e suas pressuposições básicas necessitam de constantes avaliações por parte dos administradores, a fim de verificar se ainda estão válidos e atendendo às diretrizes traçadas para o site (FONSECA; FONSECA, 2005).

Um site pode ser definido como

[...] espaço básico da informação, o website tem como principal objetivo organizá-la, estruturando uma hierarquia para que todo o conteúdo seja entendido e acessado com facilidade. A alma de um site é sua arquitetura de informação.(RODRGUES, 2005, p. 1). 
$\mathrm{O}$ autor assegura ainda que um website nada mais é que um grande arquivo. Se este arquivo estiver bem organizado, encontra-se a informação com facilidade, alcançando, desta forma, o objetivo final. Nielsen e Tahir (2002) comparam um site a uma casa onde cada janela também representa uma porta pela qual as pessoas podem entrar, seguindo os links, nos mecanismos de pesquisa de outros sites.

Um site é considerado como um "[...] recipiente para objetos com conteúdos ou documentos que os usuários navegam por meio de busca e folheio." (HAGEDORN, 2000, p. 6). O site é um “[...] espaço básico da informação, [...] tem como principal objetivo organizá-la, estruturando uma hierarquia para que todo o conteúdo seja entendido e acessado com facilidade." portanto, a objetividade deve nortear todo o conteúdo informacional ali depositado (RODRIGUES, 2005, p. 1).

Straioto (2002) assegura que a objetividade, a navegabilidade e a visibilidade que compõem o conteúdo informacional estão em direta relação com a tecnologia utilizada no site. Como o aparato tecnológico utilizado na viabilização da internet integra um campo em constante atualização, essa tecnologia dependerá sempre da avaliação do potencial do usuário, ou seja, é preciso usar os recursos certos a fim de que ele consiga acessar o conteúdo desejado.

\section{Metodologia}

A metodologia adotada foi a exploratória descritiva documental com abordagem quantiqualitativa. A pesquisa exploratória, segundo Gil (2008), tem como principal finalidade proporcionar maior familiaridade com o problema com vistas a torná-lo mais explícito. "Pode-se dizer que essas pesquisas têm como objetivo principal o aprimoramento de idéias ou a descoberta de intuições." (GIL, 2008, p. 41). Por sua vez, as pesquisas descritivas abordam quatro aspectos básicos: “[...] descrição, registro, análise e interpretação de fenômenos atuais, objetivando o seu funcionamento no presente." (MARCONI; LAKATOS, 2002, p. 20), e podem apresentar descrições quantitativas e/ou qualitativas do objeto de estudo.

A pesquisa documental tem como característica somar subsídios e aporte teórico que visam a assegurar o conteúdo a respeito do tema estudado. Ela abre a possibilidade do uso da internet, especificamente os portais e sites, tendo em vista 
que as fontes de informação são diversificadas e dispersas. Para fins de pesquisa científica, "[...] são considerados documentos, não apenas os escritos utilizados para esclarecer determinada coisa, mas qualquer objeto que possa contribuir para a investigação de determinado fato ou fenômeno.” (GIL, 2008, p. 47). Segundo Creswell, os “[...] métodos quantitativos envolvem o processo de coleta, análise, interpretação e redação dos resultados de um estudo.” (2007, p. 18) O autor afirma que a análise pode ser feita em textos e imagens, dados de entrevistas, de observação de documentos e audiovisuais. Por outro lado, a pesquisa qualitativa possibilita a análise do conhecimento e das práticas adotadas pelos participantes, “[...] considera que pontos de vista e práticas no campo são diferentes devido às diversas perspectivas subjetivas e ambientes sociais a eles relacionados.” (FLICK, 2002, p. 28).

A coleta de dados foi feita por meio de formulário, no qual foram sistematizadas quatro categorias de pesquisa fundamentadas em Nielsen (1993), Eckerson (1999) e Fonseca e Fonseca (2005), assim denominadas: (1) a interface do site é amigável para usuários eventuais; (2) classificação e pesquisa intuitiva; (3) conectividade aos recursos informacionais do site; e (4) interfaces externas. As informações foram coletadas em 27 dos 28 sites de TVs universitárias localizados, que compreendem o corpus da pesquisa, atingindo 96,5\% de cobertura dos sites, pois, durante o período de coleta dos dados, um site se manteve em manutenção.

\section{A organização da informação nos sites das TVs universitárias públicas brasileiras: resultados da pesquisa}

Conforme estabelecido na metodologia, foram delimitadas quatro categorias de pesquisa junto aos sites das TVs universitárias que serão apresentadas e analisadas a seguir.

\subsection{Categoria 1: a interface do site é amigável para usuários eventuais}

Trata da forma como o site se apresenta para os usuários de forma geral. 
Os usuários devem conseguir localizar e acessar facilmente a informação correta com o mínimo de treinamento, não importando o local de armazenamento dessa informação. (ECKERSON, 1999, p. 13).

Foram englobadas a esta categoria as seguintes questões, para reflexão e orientação à pesquisa: a linguagem utilizada no site é acessível?; consegue-se alcançar todas as seções do site?; alcança-se a informação final com no máximo quatro cliques?; disponibiliza-se função de ajuda?; disponibilizam-se meios de contato com os responsáveis?; o site informa onde o usuário está e de onde veio?; o site possui um mapa ou índice?; os usuários conseguem retornar para a página inicial e/ou anterior a partir de qualquer página?

Os resultados obtidos nos 27 sites analisados foram os seguintes: 25 apresentavam linguagem acessível ao usuário; em 23 era possível atingir todas as seções; 22 permitiam que o usuário chegasse à informação final com até 4 cliques; 25 disponibilizavam alguma forma de contato com os responsáveis pelo site ou da instituição; 7 informavam ao usuário onde ele estava na organização do site e de onde ele veio; 2 apresentavam um mapa ou índice como forma de ajuda para navegação; 7 permitiam que o usuário retornasse à página inicial ou anterior a partir de qualquer ponto e, por fim, nenhum site disponibilizava função de ajuda ao visitante.

De maneira geral, os sites apresentaram aspectos positivos e mantiveram um padrão para todas as TVs universitárias, contemplando, nessa categoria, a maioria dos quesitos essenciais, relacionados com a interface. Os elementos que interagem diretamente com o usuário, como menus, estrutura de navegação, linguagem familiar, entre outros, têm como principal objetivo facilitar a interação do site com o usuário, pois este não deve ter como obrigação adivinhar o que o sistema quer lhe dizer (NIELSEN, 1993).

A linguagem adotada no site deve ser objetiva, clara, a fim de auxiliar o usuário. Para "[...] permitir que o conteúdo apresentado comunique efetivamente com a audiência alvo, ele deve estar escrito com linguagem que seja apropriada para aquela audiência." (FONSECA; FONSECA, 2005, p. 107). Nesse quesito, a maioria dos sites atendiam às necessidades do usuário, apenas 2 utilizavam linguagem inadequada, como excesso de siglas e termos inapropriados. O site deve utilizar 
linguagem familiar ao usuário, com palavras e expressões familiares (NIELSEN, 1993).

A navegação pelo site tem sido identificada como uma exigência padrão. Ela é responsável por fazer com que o usuário chegue mais rápido até a informação que deseja. Ao verificar se o usuário conseguia acessar a todas as seções do site e se conseguia alcançar a informação final com economia de tempo, notou-se que as TVs universitárias pesquisadas têm mostrado, por meio dos seus sites, preocupação com esses aspectos. Em 23 dos 27 sites analisados, os usuários alcançavam a todas as seções da estrutura de organização, e em 22 era possível chegar à informação final com 3 ou no máximo 4 cliques. Nesse sentido, Fonseca e Fonseca (2005, p. 79) afirmam que "os usuários devem ser capazes de acessar todas as páginas críticas ou relevantes dentro de 3-4 cliques de hiper-conexão"; esse princípio contribui para assegurar que os usuários encontrem facilmente as informações disponíveis nos sites.

A ajuda ao usuário deve estar integrada às páginas do site na web (NIELSEN, 1993). Esse foi um ponto negativo detectado que compromete a relação da TVU com a comunidade, pois nenhum dos 27 sites analisados apresentou esse recurso. "Em compasso com os sistemas e tecnologias de suporte estão os processos e procedimentos humanos que dão poder à operação do website." (FONSECA; FONSECA, 2005, p. 191). As iniciativas direcionadas para a ajuda aos usuários têm grande impacto sobre a qualidade e sustentabilidade de um site, portanto, tentar estimar e certificar que as políticas de atendimento ao usuário estejam sincronizadas com os objetivos finais do site é de extrema relevância (FONSECA; FONSECA, 2005).

Em contrapartida, detectou-se, entre as funções disponíveis nos sites de 25 TVs universitárias, o "Fale Conosco" ou o "Entre em Contato". Trata-se de uma função muito positiva, pois valoriza o site e, na maioria das vezes, funciona como um canal de comunicação entre a TVU e o usuário, por meio do qual é possível solicitar ajuda, minimizando os efeitos negativos observados na análise do item anterior. A função não responde, de imediato, à aflição do usuário, porém permite que ele faça contato, a fim de dirimir dúvidas com relação ao funcionamento de determinada área ou de determinado recurso na estrutura de organização do site. 
Os sites devem, de modo geral, “[...] conter alguma informação de contato para a organização que eles representam, bem como para qualquer outra parte que os usuários alvo desejem contatar, caso eles venham a ter alguma pergunta, ou interesse." (FONSECA; FONSECA, 2005, p. 116). Estudos têm identificado que informação sobre contatos está entre os critérios-chave que o público em geral usa para avaliar a credibilidade de um site.

A informação ao usuário com relação à localização dele dentro da estrutura de navegação do site, apesar de ser um recurso de grande importância, não foi observado na maioria dos sites pesquisados. Apenas 7 deles apresentaram essa opção de navegação, e somente 2 disponibilizam mapa ou índice que permite ao usuário se localizar, retornar para a página anterior ou mesmo para a página inicial do site. "Os usuários necessitam saber onde eles estão [...] de modo a navegarem efetivamente. Isto é especialmente relevante para os maiores sites, que contêm muitas páginas.” (FONSECA; FONSECA, 2005, p. 77).

O fundamental é que os usuários sejam capazes de descobrir a sua real localização por meio do uso de recursos de navegação (links) distribuídos pelo site, possibilitando avançar e retroceder, página a página, e de usar isso a fim de saltar para outras partes do site. O site “[...] deve sempre manter o usuário informado quanto à página em que ele se encontra, como chegou até essa página e quais são suas opções de saída, isto é, onde ele se encontra numa seqüência de interações." (DIAS, 2007, p. 195). Rosenfeld e Morville (2007) propõem que um site que se preocupa em ter uma boa interação com o usuário deve responder a algumas perguntas, tais como: Onde estou?; Para onde posso ir daqui?; Que site é este?; De que trata?; Como faço para voltar à página anterior?, dentre outras.

Com base nos dados identificados e analisados na categoria "A interface do site é amigável para usuários eventuais", observou-se que a maioria dos sites das TVs universitárias atenderam aos principais itens relativos às necessidades dos usuários nos quesitos abordados. Não se pode assegurar que são sites com excelência em qualidade, mas, também, não se pode afirmar que não atinjam seu objetivo, que é disponibilizar a informação sem requerer do usuário grandes esforços para localizá-la. 


\subsection{Categoria 2: classificação e pesquisa intuitiva}

Considerou-se, para análise desta categoria, as seguintes variáveis: a disponibilização de opção de busca; a existência de opções de busca em todas as páginas; os tipos de buscas oferecidos nos sites; se há precisão nas buscas; se as informações estão dispostas em categorias; se os recursos informacionais (vídeos, programas) estão descritos; e se os termos utilizados representam o conteúdo.

No que diz respeito às questões relacionadas ao sistema de busca, os resultados foram: 13 TVs universitárias disponibilizavam o recurso em seus sites; das 13, 12 contavam com opção de busca em todas as páginas, e duas com opção de busca avançada. Foi detectada condição de precisão no resultado da busca no sistema de apenas um site, e não foi encontrada sugestão de termos para pesquisa em nenhum dos 13 sites que possuem um sistema de busca. Todos os sites localizados restringiram a pesquisa ao conteúdo do site.

A principal função de um sistema de recuperação da informação "[...] é permitir que o usuário localize o maior número possível de itens relevantes [...]" (FEITOSA, 2006, p. 28). A função de um sistema de recuperação da informação é a “[...] possibilidade de busca e recuperação, facilitando ou permitindo o acesso à informação. Seu propósito é atender a uma necessidade de informação." (MIRANDA, 2005, p. 40). Um sistema de recuperação da informação é considerado como um sistema de operações que são "[...] interligadas para identificar, dentre um grande conjunto de informações (uma base de dados [...]), aquelas que são de fato úteis, ou seja, que estão de acordo com a demanda expressa pelo usuário." (ARAÚJO JÚNIOR, 2007, p. 27).

Com base nos dados apresentados e fundamentado em Feitosa (2006), Miranda (2005) e Araújo Júnior (2007), detectou-se um cenário preocupante. Mais da metade dos sites das TVs universitárias não estão preparados para algum tipo de recuperação da informação. Tal situação denota certa desatenção pelo assunto por parte dos mantenedores dos sites e demonstra que estes não consideram que os recursos de buscas estão entre os aplicativos interativos mais úteis para os sites, "[...] o seu valor se origina do fato de reduzir o tempo de recuperação que os usuários 
devem utilizar para localizar uma informação desejada." (FONSECA; FONSECA, 2005, p. 150).

Outros pontos observados: falta da possibilidade de pesquisa avançada em 11 dos 13 sites que apresentaram um sistema de busca; nenhum site disponibilizava lista de termos; e a inexistência de precisão na recuperação da informação. O índice de precisão ou pertinência consiste na proporção de documentos relativos ao conjunto de documentos fornecidos pela pesquisa, ou seja, é a relação entre o total de itens úteis e o total de itens recuperados pelo usuário (GUINCHAT; MENOU, 1994).

Destaca-se o fato de 12 dos 13 sites analisados apresentarem a opção de busca em todas as páginas, isso é significativo para os propósitos do site e para a comodidade do usuário. A pesquisa estar restrita ao conteúdo do site também configura um fator relevante pois aumenta o seu índice de precisão. É recomendado que os sites restrinjam "[...] a pesquisa dos serviços de busca apenas ao conteúdo [...]." (DIAS, 2007, p. 198). O site deve ser capaz de indexar e organizar as informações contidas em sua base de dados. Sua máquina de busca deve refinar e filtrar as informações e apresentar o resultado da pesquisa em categorias de fácil compreensão (ECKERSON, 1999).

No que concerne à disposição da informação na estrutura organizacional do site, observou-se que em apenas 8 TVs universitárias existia a preocupação com a categorização temática como forma de organização da informação. A sistemática da organização da informação em categorias nos sites tem, como ponto de partida, o “[...] esquema de classificação, ou o conjunto de categorias que os usuários utilizam para compreender o site, e para tomar decisões sobre onde navegar." (FONSECA; FONSECA, 2005, p. 70). Trata-se de uma linguagem geralmente influenciada pelo modelo conceitual fundamental do site e a natureza específica do conteúdo (FONSECA; FONSECA, 2005).

A forma adotada por 15 dos sites analisados neste quesito era dispor o material audiovisual, por programas ou vídeos, e não por categorias temáticas. Tal iniciativa pode ser atribuída ao fato de que a produção dessas TVs é muito pequena, não havendo uma pluralidade de categorias temáticas a serem contempladas ou elencadas. As produções foram alocadas seguindo a ordem cronológica, não 
havendo a preocupação de enquadrar o conteúdo informacional em uma categoria temática específica, como documentário, cultura, ciência, entre outras. Os 4 sites restantes na análise não apresentaram nenhuma forma de organização que pudesse ser enquadrada nas situações acima.

Para se conseguir atingir a condição ideal de funcionamento do fluxo da informação em um ambiente informacional virtual, deve-se agrupar e descrever, adequadamente, cada objeto informacional (programa, vídeo, reportagem, entre outros), refletindo, inclusive, as necessidades de informação da comunidade para a qual está destinada tal produção. Um dos principais objetivos que envolve a organização dos objetos informacionais é o de agrupar sistematicamente os recursos informacionais em coleções (CAFÉ; SALES, 2010). Neste caso específico de análise, o ideal seria o agrupamento dos objetos informacionais em categorias temáticas que traduzissem o seu conteúdo.

Quando se analisou a descrição do material disponível nos sites das TVs universitárias e se os termos utilizados representavam o conteúdo informacional ali depositado, tais requisitos foram observados em apenas 11 sites, os quais atendiam parcialmente às diretrizes propostas pela CI com relação à armazenagem e recuperação da informação.

A descrição do recurso informacional, por intermédio de termos adequados, se configura no tratamento temático da informação, e é fator de extrema relevância para a sua recuperação (CAFÉ; SALES, 2010). Svenonius (2000) considera que, em uma linguagem perfeitamente ordenada, cada item tem apenas um nome e um nome é usado para se referir a cada coisa única. A autora acrescenta que a descrição da informação é a base da organização e que, neste caso, ao descrever um vídeo ou um programa, pretende-se comunicar, por meio de linguagem específica, determinados conteúdos e atributos.

A comunicação entre os ambientes de produção e de uso da informação se “[...] revela nitidamente na dimensão temática, especialmente na era da internet em que o estímulo por buscas de informação reside preponderantemente no conteúdo informacional.” (CAFÉ; SALES, 2010, p. 120).

Em concordância com os autores elencados na fundamentação teórica para análise desse item, observou-se que os sites das TVs universitárias não apresentam 
os pressupostos essenciais, defendidos pela CI, para a armazenagem e recuperação da informação. Não foram detectadas formas de tratamento da informação que contemplassem algum aspecto relativo à análise, descrição e representação do conteúdo dos documentos televisuais, o que remete o material produzido a uma condição de informação amorfa, disposta na rede, porém sem condição alguma de recuperação.

\subsection{Categoria 3: conectividade aos recursos informacionais do site}

Para a análise desta categoria de pesquisa, as questões adotadas foram: o site utiliza plataforma externa para reproduzir seus arquivos televisuais?; existe redundância de informação?; são permitidos downloads de conteúdo?; são permitidos uploads?; há um tradutor de idiomas?; o site disponibiliza alguma forma de opção de modificação do tamanho da fonte?

No que tange à utilização de recursos externos ou de plataforma para a reprodução dos conteúdos televisuais, 16 TVs universitárias adotaram o sistema de vídeo incorporado ao código fonte e à base de dados do site, porém o player utilizado para a reprodução, neste caso, para todas essas TVs, é o do YouTube, e o armazenamento do conteúdo também se dá nos servidores desta plataforma.

Observou-se que 6 TVs universitárias utilizam sistema de player construído na própria estrutura do site, e outras 5 adotaram, como formato, manter em seus sites as informações a respeito do recurso, porém com armazenamento e reprodução, por meio de links, em páginas diretamente no YouTube.

Dos 27 sites analisados, 7 apresentaram conteúdos redundantes, configurando-se em um cenário, em princípio, negativo. Porém, tal situação pode estar dentro da normalidade e caracterizada como uma ação proposital se, na análise do fato, for considerado que o conteúdo redundante nem sempre é danoso para o site, conforme afirmam Fonseca e Fonseca (2005).

Em termos positivos, “[...] existem algumas situações onde a redundância pode ser valiosa, tais como onde a persuasão, e os objetivos relacionados aos objetivos de marketing estão envolvidos.” (FONSECA; FONSECA, 2005, p. 117118). Como tal, as políticas do site, por exemplo, podem usar a informação redundante para enfatizar fatos e conduzir o usuário a certos caminhos, "[...] a 
redundância pode algumas vezes agir como uma ferramenta, ou um aparato, empregado para reforçar as mensagens, ou para persuadir uma certa visão de uma questão.” (FONSECA; FONSECA, 2005, p. 117-118).

Em seu caráter mais negativo, a redundância de informações em sites tende a refletir problemas tais como descaso com o conteúdo ou uso ineficiente de recursos, além de deixar clara uma possível falta de manutenção do site. Acredita-se que a redundância pode ocasionar confusão ao usuário, ao mesmo tempo deixando a impressão de ser um site sem avaliação ou atualização constantes. Tal fato gera insegurança e perda de tempo ao usuário.

Com relação à troca de arquivos, downloads e uploads, verificou-se que não há preocupação por parte das TVs universitárias relativa a esses quesitos. Três sites permitem downloads e apenas um permite upload de algum tipo de arquivo. $\mathrm{O}$ que é um aspecto considerado negativo para o site se for considerado que o propósito principal de sua existência é o de disseminar a informação gerada no âmbito da universidade onde a TVU se encontra inserida.

Com a restrição ao download, o usuário fica preso ao site, ou seja, todas as vezes em que ele precisar daquela informação específica, terá que retornar àquele site. Não lhe é permitido, em tese, adquirir a informação, o arquivo físico e reproduzi-lo no momento e local que desejar. O site deve permitir aos usuários publicar, compartilhar e receber informações de outros usuários. O site deve prover um meio de interação entre pessoas e grupos (ECKERSON, 1999).

Se analisada essa questão por outro prisma, a situação pode ser considerada menos negativa. Para as TVs que utilizam a plataforma do YouTube, 21 ao todo, de uma forma ou de outra, conforme descrito anteriormente, a situação se apresenta como uma possibilidade de solução. Os arquivos armazenados nos servidores do YouTube são passíveis de serem baixados para o computador local do usuário, bastando, para isso, o entendimento um pouco mais aprofundado de internet, e a utilização de softwares específicos que realizam esse processo de download. As demais TVs, 6 no total, que optaram por armazenagem e reprodução no próprio site, e que não disponibilizaram tal opção, inviabilizaram, a princípio, qualquer forma de download dos seus arquivos. 
A falta da opção de upload em 26 sites pode ser vista como uma situação danosa para a TVU, se considerados os seus principais objetivos. Tal fato se contrapõe ao diálogo com a comunidade onde o canal está inserido, pois não abre a possibilidade dessa comunidade contribuir com a programação da TV, enviando-lhe algum tipo de produção, independente ou não. Entretanto, cabe apontar que isso pode ser fruto dos objetivos e da política administrativa do canal, traçados de forma a não contemplar tal situação, o que pode ser caracterizado como falha sob o ponto de vista de Priolli e Peixoto, que definem a TVU como sendo "[...] uma televisão feita com a participação de estudantes, professores e funcionários; com programação eclética e diversificada [...].” (2004, p. 5).

Em se tratando da disponibilização de um tradutor de idiomas, percebeu-se que nenhum site das TVs universitárias pesquisadas oferecia esta opção. Esse fato é preocupante, pois muito se ouve falar, nos dias atuais, sobre a questão da inclusão. Acredita-se que esse é um assunto bastante polêmico, que caminha a passos lentos no sentido de sua concreta viabilização, mesmo em ambientes como os sites das TVs universitárias, onde esse problema já deveria ter sido resolvido. Por outro lado, esta questão pode ter sido influenciada por alguns fatores, tais como a política e o objetivo da instituição, a disponibilidade financeira, os recursos humanos capacitados para tal fim, entre outros.

Com a globalização, a internacionalização dos sites das TVs universitárias pode ser compreendida como mais uma possibilidade de audiência, configurando-se, dessa maneira, em uma demanda real e urgente por parte de usuários de outras partes do mundo. Se o produto gerado por esses canais é a informação emanada do âmbito acadêmico, e o meio de divulgação escolhido é a internet, um veículo de comunicação cuja principal característica é a inexistência de fronteiras e a democratização da informação, é de fundamental importância que essa informação seja disseminada para o maior número de pessoas possível. Entretanto, os custos de servir grupos de usuários internacionais diversificados geralmente é muito alto e, devido a isso, essa estratégia é constantemente abandonada pelas IES mantenedoras do canal (FONSECA; FONSECA, 2005). Tal situação deve explicar a total ausência do recurso de tradução nos sites pesquisados. 
No que tange à opção de modificação do tamanho da fonte, 4 TVs universitárias utilizavam esse recurso em seus sites. De acordo com Dias, as “[...] informações apresentadas em um formato (visual, auditivo, táctil) só são percebidas por pessoas que tenham esse sentido em níveis normais". (2007, p. 106). A autora acrescenta ainda que “[...] facilitar a compreensão do conteúdo informacional do produto também é essencial para o design universal." (DIAS, 2007, p. 107). Observa-se como resultado da análise deste quesito que, mesmo sendo ele uma questão também ligada à inclusão, as TVs universitárias, assim como na questão do tradutor de idiomas, parecem não atentar para a relevância e necessidade do recurso.

\subsection{Categoria 4: interfaces externas}

$\mathrm{Na}$ quarta e última categoria englobaram-se, para análise, questões relacionadas às conexões do site com outros conteúdos, tais como: a existência de links internos e externos e o funcionamento desses links.

Das 27 TVs universitárias pesquisadas, 12 apresentavam links para outros conteúdos internos da instituição, enquanto 8 apresentavam links internos e/ou externos à instituição em seus sites. Para a quantidade de sites pesquisados, 27 ao todo, é uma situação preocupante, pois os números mostram que a maioria deles parece se apresentar fechados em si, sem qualquer ligação com outros conteúdos na internet, nem mesmo com o portal da própria instituição mantenedora.

Estudos demonstram que alguns usuários consideram a escolha e a qualidade de referências a outros sites como sendo uma característica relevante do site visitado; "[...] as escolhas que um website exibe com respeito a afiliações formais ou informais podem ser usadas como uma base para julgar a credibilidade de um site." (FONSECA; FONSECA, 2005, p. 113). Os autores acrescentam, também, que "Conexões para websites externos podem ajudar os usuários a se tornarem cônscios dos preconceitos potenciais dentro de um website, uma vez que o website esteja escolhendo se associar com estes sites." (2005, p. 113).

Analisando os 20 sites que possuem conexão com outros conteúdos, sejam estes internos ou externos à instituição, detectou-se que 3 deles apresentaram problemas como links quebrados ou páginas não encontradas. Tal situação causa 
frustração ao usuário e denota abandono e desatualização do site. É fundamental a manutenção dos links ativos para que o objetivo da hiperconexão seja alcançado (FONSECA; FONSECA, 2005).

Salienta-se, ainda, que a constante atualização do site é sempre positiva, pois cria uma via de mão dupla de comunicação com os demais sites da rede que se relaciona com o site analisado. O site deve ser capaz de se comunicar/conectar com outros sites e aplicativos na rede, assim como também deve ser capaz de ser chamado/conectado por outros sites ou aplicativos, gerando, em consequência dessas interações, um processo no qual pode ocorrer a permutação de informações (ECKERSON, 1999).

\section{Considerações finais}

Se, por um lado, a universidade, por meio de suas instâncias - ensino, pesquisa e extensão -, caracteriza-se como produtora de informação, ao mesmo tempo que transforma informação em conhecimento, a TVU, por sua vez, é considerada como um dos veículos da universidade, utilizado para a divulgação dos resultados dos processos desenvolvidos no âmbito acadêmico, para tanto, utiliza diversas formas de transmissão da informação, dentre elas, a internet.

A fim de alcançar seus objetivos relativos à disseminação da informação, seja qual for o meio de transmissão, as TVs universitárias têm lançado mão de sites, onde disponibilizam seus conteúdos televisuais. Tal situação originou-se, principalmente, pela falta de estrutura física e financeira vivenciada pelas IES mantenedoras do canal, que nem sempre disponibilizam, em seus orçamentos, verbas para a implementação dos projetos da TVU.

Se os problemas dessa ordem restringiram a constituição de emissoras mais estruturadas fisicamente, com transmissão aberta ou a cabo, a internet surgiu como uma alternativa de baixo custo, porém com resultados significativos na difusão da programação do canal para a comunidade onde se encontra inserido. A utilização da internet cria, sobretudo para a TVU, a possibilidade de atingir um público ainda maior, pois, por intermédio da rede de computadores, é possível chegar a qualquer pessoa em qualquer parte do mundo. 
A organização e a representação da informação em ambiente web baseiamse na ideia de que a informação constitui a essência de um site (SOUZA, 2006). Nesse sentido, a organização da informação envolvendo seus mais diversos aspectos foi a tônica da pesquisa, que teve como objeto a análise das estruturas de organização da informação nos sites das TVs universitárias ligadas às universidades públicas brasileiras.

A utilização de plataformas externas, como o YouTube, para armazenamento e reprodução dos conteúdos televisuais produzidos pelas TVs universitárias é um fator preocupante se considerado que, como se trata da prestação de um serviço sem custos para as TVs, este pode ser suspenso a qualquer momento. Em decorrência, aquela TV que não constituiu um acervo particular da coleção, corre o risco de perder a sua memória institucional.

O estudo também revelou situações positivas e negativas envolvendo os canais universitários. Foram algumas ocorrências pontuais e outras mais abrangentes; apesar disso, acredita-se que as TVs universitárias estão desempenhando seu papel, representando a universidade junto à sua comunidade e, com o auxílio da internet, extrapolando os limites dessa representatividade para outras regiões e pessoas.

\section{Referências}

ASSOCIAÇÃO BRASILEIRA DE TELEVISÃO UNIVERSITÁRIA.Carta de Diretrizes das Televisões Universitárias Brasileiras. Brasília: ABTU, 2009. Disponível em: 〈http://www.abtu.org.br/noticias/noticias_da_abtu/366 > . Acesso em: 17 ago. 2014.

\section{ARAÚJO JÚNIOR, R. H. Precisão no processo de busca e recuperação da} informação. Brasília: Thesaurus, 2007.

BACCO, T. S. Televisão universitária online: a experiência da TV UERJ, a primeira do Brasil. 2010. Dissertação (Mestrado em Comunicação) - Universidade Estadual de Londrina, Londrina, 2010.

BRASIL, A. C. Telejornalismo, internet e guerrilha tecnológica. Rio de Janeiro: Ciência Moderna, 2002. 
BUCKLAND, M. What kind of Science can Information Science be? Journal of the American Society for Information Science and Technology, Berkeley, v. 63, n. 1, p. 1-7, Oct. 2011.

CAFÉ, L.; SALES, R. Organização da informação: conceitos básicos e breve fundamentação teórica. In: ROBREDO, J.; BRÄSCHER, M. (Org.). Passeios no bosque da informação: estudos sobre representação e organização da informação e do conhecimento. Brasília: IBICT, 2010. p. 115-129

CASTELLS, M. A galáxia da internet: reflexões sobre a internet, os negócios e a sociedade. Rio de Janeiro: Jorge Zahar, 2003.

CHOO, C. W. A organização do conhecimento. 3. ed. São Paulo: Senac, 2003.

CRESWELL, J. W. Projeto de pesquisa: métodos qualitativo, quantitativo e misto. 2. ed. Porto Alegre: Artmed, 2007.

DIAS, C. Usabilidade na web: criando portais mais acessíveis. 2. ed. Rio de Janeiro: Alta Books, 2007.

ECKERSON, W. 15 rules for enterprise portals. Oracle Magazine, Redwood Shores, v. 13, n. 4, p. 13-14, July/Aug. 1999.

FEITOSA, A. Organização da informação na web: das tags à web semântica. Brasília: Thesaurus, 2006.

FLICK, U. Introdução à pesquisa qualitativa. 3. ed. Porto Alegre: Artmed, 2002.

FOGL, J. Relations of the concepts 'information' and 'knowledge'. International Forum on Information and Documentation, The Hague, v. 4, n. 1, p. 21-24, 1979.

FONSECA, A.; FONSECA, A. F. Avaliando websites. João Pessoa: UNIPÊ, 2005.

FUJITA, M. S. L. A biblioteca digital no contexto da gestão de bibliotecas universitárias: análise de aspectos conceituais e evolutivos para a organização da informação. In: ENCONTRO NACIONAL DE CIÊNCIA DA INFORMAÇÃO, 6. 2005, Salvador. Anais... Salvador: UFBA, 2005.

GIL, A. C. Como elaborar projetos de pesquisa. 4. ed. São Paulo: Atlas, 2008.

GUINCHAT, C.; MENOU, M. Introdução geral às ciências e técnicas da informação e documentação. Brasília: MCT, 1994.

HAGEDORN, K. The information architecture glossary. [S.1.]: Argus Center for Information Architecture, 2000. Disponível em: <http://argus-

acia.com/white_papers/iaglossary.html >. Acesso em: 05 jul. 2014. 
HIDALGO GOYANES, P. La documentación audiovisual de las televisiones. La problemática actual y el reto de la digitalización. Documentación de las Ciencias de la Información, Madrid, v. 28, p. 159-171, 2005.

HJØRLAND, B. Epistemology and the socio-cognitive perspective in Information Science. Journal of the American Society for Information Science and Technology, Hoboken, v. 53, n. 4, p. 257-270, 2002.

MARCONI, M. de A.; LAKATOS, E. M. Técnicas de pesquisa: planejamento e execução de pesquisas, amostragens e técnicas de pesquisa, elaboração, análise e interpretação de dados. 5. ed. São Paulo: Atlas, 2002.

MCGARRY, K. O contexto dinâmico da informação. Brasília: Briquet de Lemos, 1999.

MIRANDA, M. L. C. Organização e representação do conhecimento: fundamentos teórico-metodológicos na busca e recuperação da informação em ambientes virtuais. 2005. Tese (Doutorado em Ciência da Informação) Universidade Federal do Rio de Janeiro, Rio de Janeiro, 2005.

MIRANDA, M. L. C.; GARBELINI, M. F. Tratamento técnico da documentação audiovisual na TV da Universidade Federal de Goiás. In: ENCONTRO NACIONAL DE PESQUISA EM CIÊNCIA DA INFORMAÇÃO, 12. 2011, Brasília. Anais... Brasilia: ENANCIB, 2011.p. 439-451

NIELSEN, J. Usability engineering. New York: Academic Press, 1993.

NIELSEN, J.; TAHIR, M. Homepage usabilidade: 50 websites desconstruídos. Rio de Janeiro: Campus, 2002.

PRIOLLI, G.; PEIXOTO, F. A TV universitária no Brasil: os meios de comunicação nas instituições universitárias da América Latina e Caribe. São Paulo: ABTU, 2004. Disponível em: <http://unesdoc.unesco.org/images/0013/001399/139903por.pdf >. Acesso em: 03 de fev. 2014.

RAMALHO, A. A TV universitária como ponte entre a produção cientifica e as massas: a TV FEMA de Assis (SP). 2005. 148 fls. Dissertação (Mestrado em Comunicação: Mídia e Cultura) - Universidade de Marília, São Paulo, 2005.

RAMALHO, A. O perfil da TV universitária e uma proposta de programação interativa. 2010. Tese (Doutorado em Estudo dos Meios e da Produção Mediática) Universidade de São Paulo, São Paulo, 2010.

RODRIGUES, B. Site ou portal? As diferenças entre site, portal, hotsite e minisite. Postado em 18 abr. 2005. Disponível em:

<http://webinsider.com.br/2005/04/18/site-ou-portal/>. Acesso em: 5 jul. 2014. 
ROSENFELD, L.; MORVILLE, P. Information architecture for the word wide web. 3. ed. Sebastopol: O’Reilly, 2007.

RUBIO, A. La documentación audiovisual en el centro territorial de TVE en la Rioja. Berceo, La Rioja, n. 144, p. 215-233, 2003. Disponível em: $<$ http://dialnet.unirioja.es/servlet/ articulo? codigo $=698051>$. Acesso em: 18 jun. 2014.

SOUZA, R. R. Sistemas de recuperação de informações e mecanismos de busca na web: panorama atual e tendências. Perspectivas em Ciência da Informação, Belo Horizonte, v. 11, n. 2, p. 161-173, maio/ago. 2006.

STRAIOTO, F. A arquitetura da informação para a world wide web: um estudo exploratório. 2002. Dissertação (Mestrado em Ciência da Informação) Universidade Estadual Paulista Júlio de Mesquita Filho, Marília, 2002.

SVENONIUS, E. The intellectual foundation of information organization. Cambridge: MIT, 2000.

WANDERLEY, L. E. W. O que é universidade. 7. ed. São Paulo: Brasiliense, 1998.

\title{
The organization of information on the websites of Brazilian public universities televisions
}

\begin{abstract}
The study analyzes the organization of information on the websites of Brazilian public universities TVs, investigating the number of TVs present in public IES (Institutions of higher education) and, among them, which use the Internet to spread the produced content. The research is documentary, exploratory and descriptive, with quantitative and qualitative approach. The result shows 102 IES; $42.2 \%$ of them produce television and, among these, more than half uses the internet as means of dissemination. It is concluded that the websites of TVs do not have the minimum requirements of organization that allow for an efficient storage and retrieval of the information.
\end{abstract}

Keywords: Organizing information on websites. University TV. Audiovisual document. Televisual document.

Recebido em: 09/03/2015

Aceito em: 17/09/2015 